\title{
Engaged Dialogic Pedagogy and the Tensions Teachers Face
}

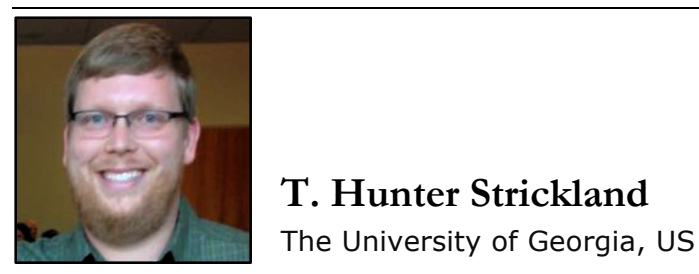

\begin{abstract}
Book review: Fecho, B., Falter, M., \& Hong, X. (2016). Teaching outside the box and inside the standards: Making room for dialogue. New York: Teachers College Press.

This review highlights the editors' vision of showing the power of engaged dialogic practice in classroom contexts that are at odds with the push for the standardization of schools and learning. In particular, this review will show how the individual stories of the four teachers highlighted in the book along with the experience of the university researchers created a dialogue from which readers can take hope that their choice to engage in Bakhtinian dialogism in the context of their classrooms is a worthy pursuit. According to the book, this is true even when that choice puts them at odds with other teachers, administrators, and state or national standards. This review will show that the editors and the teachers whose stories are told do not intend for their readers to come to this text ready to join the fight against standards, but for them to be able to see how dialogue is exceptionally important in working in standardized spaces. The book itself is short with only six chapters and just over one hundred pages, therefore, the review will address each chapter individually and its overall engagement with the purpose outlined above. Each chapter ends with the author's suggestions for action which can help the reader new to dialogical pedagogy grasp dialogical strategies.
\end{abstract}

Keywords: Bakhtin, Standards, Dialogue, Teaching, Engaged Dialogic Practice

T. Hunter Strickland is a doctoral candidate in Language and Literacy Education and Graduate Teaching Assistant in English Education at The University of Georgia. His research interests are in dialogic pedagogy and the use of young adult literature in both secondary schools and teacher education programs. Additionally, he is interested in using Bakhtin's concepts in analyzing young adult literature in order to engage with young adult texts and the students who read them.

$\cos \cos 80$

The struggle for so many educators that want to create a dialogical classroom is that none of us have a clear roadmap for making that happen. We all know the importance of paying mind to the authoritative discourses that are at play in classroom spaces, but teachers often find it difficult to allow for a truly ever-changing and evolving heteroglossia, or "other tongues" (p. 12), in spite of them. Fecho, Falter, \& Hong (2016a) share that "In Bakhtin's dialogical theory, one source of tension is the constant tug of war between authoritative discourses and internally persuasive discourses" (p. 4). This book recognizes this struggle in the age of standardization knowing full well that "As more and more testing and standardization happens in schools, teachers are metaphorically and literally swimming upstream against rough and exhausting currents that are leading the focus away from the individual and more toward the common" 


\section{Engaged Dialogic Pedagogy and the Tensions Teachers Face}

T. Hunter Strickland

(Fecho, Falter, \& Hong, 2016b, p.xiv). This book engages with the tensions of heteroglossia and monoglossia as they come into contact with both authoritative and internally persuasive discourses in schools. The editors of this book decide to make their case for engaged dialogic practice (p. 97) through the telling of stories and how the stories that are told in classroom spaces will either further the tide of standardization or help others break away from it.

In "The Story of This Book," the first of chapter out of six, the editors not only provide the context for themselves, the researchers, and the teachers whose stories are told, but they also provide a framework for the reader to understand what dialogical pedagogy is as well as the nature of wobble moments, their key to the following stories, where "...the equilibrium of their [teacher's] belief system—what counts for them as good teaching and how best to work with diverse groups of adolescents-is put into sway" (p. 5). The editors show in this introductory chapter that it is in these wobble moments when teachers have a chance to choose dialogue or not that we then learn what engaged dialogical practice really is. The intent of this concept of the wobble for teachers is good as the foundation for understanding the tensions at play within the discourses and heteroglossia within a school. However, the wobble moment and the examinations of tensions within teaching are much easier to understand for the established teacher such as the four teachers highlighted in the text or the editors themselves, but what this text is missing is how the dialogic moment can be planned and prepared for with the preservice or new teacher struggling with the new responsibilities of teaching and managing a class. For the preservice or new teacher, we that have been there know, the centripetal (Bakhtin, 1981a, p. 270) and centralizing forces hoping to reify our teaching to tradition and standard are hard to deal with as they work to cover curriculum, plan and assess, and feel the burden of outside-the-class school duties for the first time. How do new teachers go into a context where the monoglossia of traditional teaching is valued, and how do they make room for dialogue anyway? How do we teach new teachers of, as Bakhtin explained, "The living utterance, having taken meaning and shape at a particular historical moment in a socially specific environment, cannot fail to brush up against thousands of living dialogic threads, woven by socio-ideological consciousness around the given object of an utterance; it cannot fail to become an active participant in social dialogue" (p. 277). How does the living utterance exist in our classrooms?

The important message throughout the book is that none of us who choose to call ourselves dialogic teachers get it right all of the time. None of us have perfect dialogic classrooms, but we choose to go for it anyway. This first section of the book ends with an attempt (and one of the best ones l've seen) to give a crash course in what engaged dialogic practice is, however imperfect, and introduce the reader to the theoretical foundation of Mikhail Bakhtin and dialogic pedagogy. The great value here, and the reason I will use this book with my preservice teachers, is that an unfamiliar reader can be introduced to dialogism, Bakhtin, and the inherent tensions and wobble moments that come from engaged dialogic practice in a relatively short time and have the foundation necessary to understand the teacher stories that are the bulk of this text. The perfect reader of this text, though, is the teacher educator or established teacher who has some foundation in dialogic pedagogy and at least a cursory understanding of Bakhtin's work. Otherwise, the reader might be disappointed that more space was not given to unpack and dive deeper into the theoretical foundation of Bakhtin's work.

In the second chapter, Paige's story highlights the tension of stakeholders outside the dialogic classroom that misunderstand a teacher's motives because of the pressure of standardized assessment. Paige, a social studies teacher, shares the story of a parent email that she received after she and Michelle, one of the researchers, diverge briefly from direct instruction and engage in a class discussion of No Child Left Behind as it related to their work on Jefferson's inaugural address and the philosophies of several of 
the founding fathers. The parent sent an email asking why Paige was not focused entirely on the graphic organizer that would be used for a quiz later that week instead of discussing No Child Left Behind.

Paige shares in her story the hurt and defensiveness that she felt upon receiving this email, but reflects how it only highlighted a piece of the much larger picture of instruction that day. Paige shares that "My student may have been longing for a list of things to memorize instead of a bunch of concepts and ideas that we were weaving together through discussions" (p. 19). In Paige's wobble moment, one where she felt the pressure of many discourses at play within her classroom, she had to choose to do what was best for all of her students in spite of the pressures of standardization. This highlights Bakhtin's notion that "Every concrete utterance of a speaking subject serves as a point where centrifugal as well as centripetal forces are brought to bear" (Bakhtin, 1981a, p. 272). The centripetal forces of standardization pushed this parent to demand that quiz preparation be the only focus where Paige and Michelle knew that the centrifugal forces of a living heteroglossia called for so much more. The reader is left with an important message that "Teachers can be dialogical and create classrooms that are alive without sacrificing good test scores, skirting expectations, and acting as subversives" (Fecho, Falter, \& Hong, 2016b, p. 25). Instead, dialogical teachers are flexible and leave their classrooms open to whatever whim and direction that heteroglossia takes them.

The English and social studies teacher as reader of this section is going to find much they can relate to. In fact, any teacher will recognize the tension between standards, parent expectations, and their teaching. The reader is left wondering how can I be okay with the messiness of dialogic pedagogy, what about the pressure of someone outside of my class judging my teaching when they do not know or understand the theoretical foundation for what I am doing in my class with my students? Most importantly, the section needed some action steps to providing rationales for how dialogic pedagogy is valuable and can enhance and not sacrifice test scores. I know that in my own experience it was difficult to know that the unfinished nature of the heteroglossia in my classroom meant that I had to be willing to let go of control. There were no other teachers in my school that engaged in dialogic pedagogy, so, I at times felt alone and judged for how I ran my classroom. What would the featured teachers or editors say about this idea? How would they encourage teachers to join professional networks where they will be supported and encouraged? If it is true that "many secondary English teachers don't open themselves to dialogical relationships. They worry that by validating students' personal searches for meaning, their own identities as teachers and the traditional culture of the classroom will spin out of their control and chaos will reign" (Fecho \& Amatucci, 2008, p. 6), then how do we teach new teachers that this is okay? .

Lisa's story in the next chapter highlights another tension that dialogic teachers will come up against, and that is when engaged dialogic practice puts teachers in opposition with their colleagues and administrators. Early, Lisa shares that "...dialogic practice has an amazing capacity for diminishing the hierarchies that set me apart from my students" (p. 33). With this ability, Lisa is able to form close bonds with her students through vulnerability and openness. Her story of wobble explains a moment in a professional learning meeting at school where a student of hers, Emilio, was to be brought before a group of teachers to explain his underperformance. Lisa, with the close relationship and personal connection to Emilio gained through a dialogic classroom, stood up for Emilio and ushered him away from what could have been a horrifying and uncomfortable experience. Lisa says, "I was also angry about the agenda of the meeting. There was no invitation to discuss how we might approach or inquire into the problem of student failure in our school" (p. 37). Lisa felt the need to use her position in Emilio's life to stand up against the authoritarian voice of the administration who had decided to bring several students in to this meeting. 
The nature of dialogic teaching provides a much more personal connection to the lives of students, and as such, Lisa would attest, this gives teachers a duty to speak for the well-being of students when the authoritative voices of a school do not value their voices as students. This is much easier said than done, however. The reality is that it is difficult to stand up against a school culture, administration, and other teachers who do not believe the same things about teaching that we do. Choosing dialogic pedagogy does not mean that we believe that our way is the only way, or the only right way, but that we must be willing to stand up against those who may have power over our jobs in choosing to protect our students. This is noble, no doubt, but this section perhaps makes it seem easier than it might have actually been for Lisa. Tension with colleagues and administrators is much the focus of this chapter, but the grinding difficulty that that choice can be could have been given more space.

This section has much merit, however. Lisa reflected Bakhtin's notion that "One's own discourse and one's own voice, although born of another or dynamically stimulated by another, will sooner or later begin to liberate themselves from the authority of the other's discourse" (Bakhtin, 1981a, p.348). She had to stand up against the authoritative voice that would have potentially humiliated her student. When she did this, Lisa heard all kinds of negative reactions to her taking the student from the meeting. Many thought she was too emotional or overstepping her bounds, but Lisa, sharing the vulnerability and imperfection of her reaction, tells the reader that "Perhaps this is the charge of the dialogical teacher-to open discussion of those big issues so as to lessen the need for so many micro-interventions" (Fecho, Falter, \& Hong, $2016 b$, p. 39). Lisa ends her chapter by making the case for engaged dialogic practice as a rigorous space that also engages student learning with their personal connections to their lives. Lisa's chapter is evidence of a great willingness for vulnerability in front of and for her students. The emotional toll on her teaching life was taxing, but worth it. I wonder though how difficult it would seem or how not worth it dialogic teaching might seem to a new teacher who just wanted to put their heads down, go with the flow, and get their work done? Is a willingness to rock the boat a requirement of the dialogic teacher? Personally and reflectively, these choices were worth it for Lisa as she grew as a teacher, but it is a difficult choice to teach in this way, and in some ways teachers have to be willing to subject themselves to this difficulty year after year.

lan's story in the next chapter engages the reader in many concepts of note. First, he shares how state and national standards, in particular the Common Core state standards for English, actually “...gives English teachers the freedom to do nearly anything we want in the classroom and call it standards based; on the other [hand], it makes knowledge claims based on the learning of language arts standards nearly vacuous" (p.47). He goes on to explain that standards can create a counterfeit schooling that dialogical pedagogy, in some ways, fights back against. Standards, he explains, too often are used merely to check off a box of "good teaching" whether or not a teacher is doing anything of substance. Thus, this chapter is the first to really hit the promises that the title implies.

lan's story tells of the tensions of heteroglossia in the classroom as well as the ethical and legal tensions that come into play in a dialogical classroom. He shares an experience where a state senator accosts an undocumented immigrant who was a high school student of lan's. He explains how he, lan, had to stand up for and protect his student against the authoritative voice of the senator, and how "The tension between the legal and ethical here consists of how the roles of citizen, teacher, and employee separate and conflate" (p. 50). In his dialogical classroom, lan has to listen to the internally persuasive discourses that evolve his thoughts and actions while allowing for dialogue to happen in the heteroglossic environment he is in with his students (Bakhtin, 1981a, p. 346). This can be exceptionally difficult in a classroom especially when teachers come into contact with discourses that they personally disagree with. lan shares the difficulty in a dialogical classroom of allowing students' transactions with a text be theirs and not to force them to find meaning according to his opinions. 
More analysis of the varying discourses that all teachers would be in contact with in a school could be explained especially considering the authoritative discourses of standards and state representatives who make decisions for educators and students across the state. These discourses also come into play with the local discourses of county officials and administrators within a school. It is under all of these varying authoritative discourses seeking to centralize that teachers and students operate. How can a teacher choose to work towards the social justice issues affecting their students while also under the frame of required standards? This chapter does give some practical advice on changing activities to be more dialogic, but dialogic pedagogy requires our work to be unfinished and always in the process of becoming and evolving. How or why then do teachers take the risks associated with the vulnerability and freedom that dialogic pedagogy provides? Can teachers find "a shift towards a more collaborative teaching culture-a culture based on dialogue, reflection, and the sharing of ideas-[that] can supplant the unproductive hierarchy between teacher and students and maximize opportunities for teaching and learning to occur" (Stewart \& McClure, 2013, p. 95)?

In the final chapter showcasing the story of a teacher's wobble moments, Angela's story addresses the discourses present in her school. In particular, she starts her chapter by explaining the myriad authoritative voices in the school, and how the social constructions within the school position teachers and administrators at the top of the hierarchy while "...it positioned students as powerless in that they had no voice" (Fecho, Falter, \& Hong, 2016b, p. 67). She explains how those engaged in dialogical practice are often small islands of dialogue within a much larger monologic space (p.68). She calls for teachers to help flatten the hierarchies present in their school and to work to become an equal with the student to create a truly dialogical classroom.

Angela's moment of wobble comes from a class discussion on race within a text. Her tension comes when a white student responds in a way that the rest of the class reacts with discomfort. Angela knows that any number of reactions on her part can have negative influences on all the students in the class, and, ultimately, the lesson ends with an unsatisfactory response on her part. She explains that "This is the challenge of the dialogical classroom. Students explore their voices, and in a diverse classroom, their voices are not always going to align with their classmates" (p.72). The struggle for the teacher becomes not to jump in to control the discussion when such disagreements happen. However, the most important lesson that Angela shares for the reader is that we cannot remove bias, but "... what the dialogical classroom offers is a way in which to have those agendas and biases voiced, while also listening to and understanding others" (p. 76). This is the great hope of engaged dialogic practice. Power must be shared so that the many voices of a classroom can create meaning together. The only question to contemplate, though, is: but how difficult is it for teachers and teacher educators to keep our mouths shut in a classroom?

The essence of this chapter is true, we must provide more space for the voices of our students to be heard in our classrooms, but isn't the unsaid end of that sentence "within reason?" Teachers invested in dialogic pedagogy do not create or plan for chaos to rule their classrooms. The reality is that we are held to standards, we have annual evaluations tied to our names forever, and we are all working for somebody. So, how do we make room for the heteroglossia and it not become a free-for-all? We cannot completely give up our power as teachers in the classroom; parents, administrators, and school boards all give us that power and a paycheck to teach a curriculum to students, so what do we do when any stakeholder questions what we are doing in our classrooms as they see a dialogic and heteroglossic mess through the classroom door window?

The final chapter of the book readdresses the major tensions discussed throughout. The editors explain each tension and, more importantly, give the reader lessons on what can be learned from them. 
Engaged dialogical practice is not easy, but the editors finish the book with practical advice for how a newcomer could choose moments of dialogue even when they are difficult. This information is valuable, and present throughout all other chapters, but as it is most likely what the reader is looking for when picking up this book; so, the authors could have featured the advice in more length and depth tied to each chapter's narratives. One critique of this book is that every chapter ends with a one to two page action steps section by each chapter author. This information is both summary and a how-to guide, but for the reader looking for even more, they might be disappointed that more room was not spent going into more depth.

Overall, the editors push readers to become reflective educators that are constantly in dialogue with the many discourses that surround them. The dialogic teacher is constantly evolving. Standards driven instruction does not hamper the dialogic teacher, but the dialogic teacher holds themselves to a much higher standard and one that cherishes the living heteroglossia of the classroom (p. 104). This text provides an introduction to engaged dialogic practice that would be a worthy start to what we mean by dialogic pedagogy, and focuses on "Making authentic dialogue the centerpiece of instruction [which] creates spaces for teaching and learning to become a multi-voiced activity that offers both teachers and students the opportunity to be active participants in meaning making" (Stewart, 2010, p. 6).

While part of me is always looking for the perfect text on dialogic pedagogy, I know that it does not exist, and this book is the closest that I have felt to that practical need in dialogic pedagogy. As I read this text, all of my history as someone who wanted to be an engaged dialogic teacher was in conversation with the editors and the teachers who told their stories. My first experiences with dialogic pedagogy where in Bob Fecho's classes during my master's degree at the University of Georgia. He taught me that the heteroglossic nature of the classroom needed to be given space for our many voices to engage in dialogue. It was a revolutionary idea for me as I had to realize that the hierarchies between student and teacher needed to be shifted so that every voice had a place in the classroom because they were competing to be heard. Bakhtin (1981b) wrote about the active nature of the polyglossia in the novel which we then extrapolate to our understandings of the nature of a classroom. He said, "Where languages and cultures interanimated each other, language became something entirely different, its very nature changed: in place of a single, unitary sealed-off Ptolemaic world of language, there appeared the open Galilean world of many languages, mutually animating each other" (p. 65). This is directly applicable to pedagogy. In teaching, historically, the teacher's language has been the one voice of value in a classroom. Student voices that were then animating and engaging with each other were seen as language to be silenced. Thus, the language of the teacher was privileged, and the language of the student was quieted. Many classrooms unfortunately still operate in this fashion.

Fecho's work, long before this book came out, has always been to help teachers move beyond the privileged language paradigm of the classroom, and to help teachers begin to see that the many voices in their classrooms are something to embrace. Fecho \& Ammatucci (2008) argued that "many secondary English teachers don't open themselves to dialogical relationships. They worry that by validating students' personal searches for meaning, their own identities as teachers and the traditional culture of the classroom will spin out of their control and chaos will reign" (p. 6). Teaching Outside the Box but Inside the Standards helps make that choice possible. The book takes Bakhtin's idea about language that "We live, write and speak today in a world of free and democratized language; the complex and multi-leveled hierarchy of discourses, forms, images, styles that used to permeate the entire system of official language and linguistic consciousness was swept away by the linguistic revolutions of the Renaissance" to heart, and this shows the reader that making the choice as a teacher to walk a dialogical path is worth it for their teaching and for their students. (Bakhtin, 1981b, p.71). Fecho, Falter, \& Hong show in this text that the chaos that many 
teachers are afraid of is naturally how their students' communication works, and how it can best develop as an active and evolving force.

Fecho, Falter, \& Hong give readers a crash course in what they mean by engaged dialogic pedagogy in this text, and, in such a short space, I am left wanting more. However, this want for more is born out of the excitement for what the editors have accomplished. Each of the vignettes told in this book end with suggestions for action for teachers to put dialogic pedagogy into practice. These couple of pages at the end of each chapter give practical advice for those who are new to dialogic pedagogy, and each time I read one I applauded with how helpful they were, but I wanted those sections to be much longer and more developed. What student teachers especially want are examples of what they will see in their classrooms, and how to handle those situations when they come. These steps for action section are a start to answering this need.

These sections are helpful as they give steps for teachers to follow when they are given an opportunity to choose dialogue in their classroom or school contexts. As I am now a doctoral student teaching in the English teacher preparation program at the University of Georgia, I am using this text to expose my students to Batkhin and dialogism in a practical way and not only with the theoretical. As I immerse myself in the original texts of Bakhtin to make my own sense of them, I am glad that I can have such a great book of practice alongside my study. I wish I had had this text years ago when I was first becoming an English teacher because it explains dialogic pedagogy in an understandable way. This would have helped me start on a less rocky path to dialogic teaching as a high school teacher with a better rationale for what I believed in. I would not, then, have just had to try to figure it out alone as I went along. It allows me to have conversations with my students based on the real stories of teachers choosing engaged dialogic practice, and the book allows my students to engage in an open dialogue on what it means to give space for the heteroglossia that surrounds them in their new schools, and prepare them to face the tensions of authoritative discourses in education as they reflect on the various internally persuasive discourses that move them, and this is the book's greatest strength.

\section{References}

Bakhtin, M. M. (1981a). Discourse in the novel. In M. Holquist (Ed.), The dialogic imagination: Four essays (C. Emerson \& M. Holquist, Trans.) (pp. 272-348). Austin, TX: University of Texas Press.

Bakhtin, M. M. (1981b). From the prehistory of novelistic discourse. In M. Holquist (Ed.), The dialogic imagination: Four essays (C. Emerson \& M. Holquist, Trans.) (pp. 272-348). Austin, TX: University of Texas Press.

Fecho, B., \& Amatucci, K. B. (2008). Spinning out of control: Dialogical transactions in an English classroom. English Teaching: Practice and Critique, 7(1). 5-21.

Fecho, B., Falter, M., \& Hong, X. (2016a). Embracing tension: using Bakhtinian theory as a means for data analysis. Qualitative Research, 17(1), 20-36.

Fecho, B., Falter, M., \& Hong, X. (2016b). Teaching outside the box and inside the standards: Making room for dialogue. New York: Teachers College Press.

Stewart, T.T. (2010). A dialogic pedagogy: Looking to Mikhail Bakhtin for alternatives to standards period teaching practices. Critical Education, 1(6). 1-20. 
Stewart, T.T. \& McClure, G. (2013). Freire, Bakhtin, and collaborative pedagogy: A dialogue with students and mentors. International Journal for Dialogical Science, 7(1), 91-108.

\section{(c)) EY}

New articles in this journal are licensed under a Creative Commons Attribution 4.0 United States License.

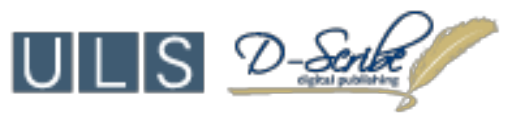

This journal is published by the University Library System, University of Pittsburgh as part of its D-Scribe Digital Publishing Program and is cosponsored by the University of Pittsburgh Press. 